\title{
LITERASI DIGITAL
}

\section{Penulis}

Institusi

Email Korespondensi

DOI

Kata Kunci:

Literasi digital

Memahami

literasi

digital

Tekhnologi digital

Keywords:

Digital literacy

Understanding digital

literacy

Digital technology

\section{: Haickal Attallah Naufal}

: Fakultas Ilmu Sosial dan Ilmu Politik, Universitas Muhammadiyah Jakarta

: hii.kall171@gmail.com

: $10.53947 /$ perspekt.v1i2.32

\begin{abstract}
Abstrak
Literasi digital merupakan suatu bentuk kemampuan untuk mendapatkan, memahami dan menggunakan informasi yang berasal dari berbagai sumber dalam bentuk digital. Literasi ini sendiri dalam konteks pendidikan berperan dalam mengembangkan pengetahuan seseorang pada materi pelajaran tertentu serta mendorong rasa ingin tahu dan mengembangkan kreativitas yang dimiliki. Hal inilah yang menuntut mahaiswa agar memiliki literasi atau kemampuan untuk mengolah dan memahami informasi yang baik untuk dipelajari dan di mengerti dengan begitu perkembangan teknologi yang sangat pesat, memungkinkan mahasiswa untuk lebih muda dalam mengakses informasi. Literasi digital juga sangat diperlukan untuk mengatasi masalah ledakan informasi yang terus meningkat di dalam sumber digital. Masyarakat kini dihadapi dengan perkembangan teknologi yang sangat pesat masyarakat juga dituntut untuk memilah dan memilih Informasi yang sesuai dengan keadaan yang sebenarnya. Paparan berbagai macam informasi dari media membuat kebanyakan orang ragu akan informasi yang benar dan tidak benar adanya. Maka dengan adanya fenomena tersebut, pengetahuan literasi media sangat dibutuhkan sebagai kemampuan untuk mengolah informasi. Dalam hal ini Penyalahgunaan teknologi digital dapat berdampak buruk bagi kehidupan pribadi dan sosial. Oleh karena itu literasi digital perlu dikembangkan untuk membangun karakter bangsa guna menciptakan generasi yang cerdas dan kaya akan informasi serta kritis dalam memilih informasi yang baik dan benar. Dimensi literasi digital meliputi alat dan sistem, informasi dan data, berbagi dan kreasi, konteks sejarah dan budaya. Melalui pemahaman terhadap dimensi dimensi tersebut dapat dikembangkan menjadi materi yang dapat membantu seseorang untuk lebih kritis dalam memilih Informasi.
\end{abstract}

\section{Abstract}

Digital literacy is a form of ability to obtain, understand and use information from various sources in digital form. This literacy itself in the context of education plays a role in developing one's knowledge on the certain subject matter and encouraging curiosity and developing one's creativity. This is what requires students to have literacy or the ability to process and understand information that is good to learn and understand, so the rapid development of technology allows students to access information more easily. Digital literacy is also very much needed to overcome the problem of the ever-increasing explosion of information in digital sources. Society is now faced with very rapid technological developments; people are also required to sort and choose the information that is under the actual situation. Exposure to various kinds of information from the media makes most people doubt whether the information is true or not. So, with this phenomenon, knowledge of media literacy is needed as the ability to process information. In this case, the misuse of digital technology can harm personal and social life. Therefore, digital literacy needs to be developed to build the nation's character to create a generation that is intelligent and rich in information and critical in choosing good and correct information. Dimensions of digital literacy include tools and systems, information and data, sharing and creation, historical and cultural contexts. Through an understanding 
of these dimensions, it can be developed into material that can help someone to be more critical in choosing information.

\section{PENDAHULUAN}

Di era revolusi keempat atau 4.0 yang dikenal dengan revolusi digital, semua informasi dapat diperoleh dengan real-time dan cepat dimana saja dan kapan saja. Adanya mesin pencari membantu seseorang mencari bahan rujukan yang diinginkannya secara cepat. Hal ini karena informasi dan aktvitas interaksi media telah terdigitalisasi oleh kemajuan teknologi. Friedman dalam Afandi dkk. mengilustrasikan perubahan ini sebagai "the world is flat" - yang merujuk pada sebuah keadaan dimana dunia tidak terbatas pada batas-batas negara dan zona waktu karena perkembangan teknologi (Afandi dkk., 2016; Friedman, 2007). Perkembangan teknologi informasi telah menciptakan sebuah "ruang baru" yang bersifat artifisial dan maya, yang disebut cyberspace (Pilliang, 2012). Perkembangan teknologi informasi direspon dengan adanya penetrasi dan perilaku penggunaan internet Indonesia yang mengalami pertumbuhan dari tahun ke tahun. Hasil survey APJII (Asosisasi Penyelenggara Jasa Internet Indonesia) menyebutkan bahwa terdapat peningkatan pengguna internet di Indonesia sejak 2016. Ini memunculkan Perkembangan teknologi informasi menjadi bagian dari mulai nya era revolusi digital di Indonesia. Perkembangannya yang sangat pesat mampu memberikan pengaruh besar dan mendominasi seluruh sektor kehidupan masyarakat, termasuk di dunia pendidikan. Tuntutan akademik pada tiap jenjang pendidikan di Indonesia berbedabeda (Akbar
\& Anggraeni, 2017). Digital-age dalam dunia pendidikan, khususnya pada pendidikan tinggi, memiliki konsekuensi berupa desain pembelajaran dengan memanfaatkan media digital sebagai sarana untuk meningkatkan pengetahuan mahasiswa. Media digital dapat menyajikan materi pembelajaran secara kontekstual, audio maupun visual secara menarik dan interaktif (Umam, Kaiful; Zaini, 2013). Universitas sebagai bagian dari lembaga pendidikan tinggi sudah selayaknya menyesuaikan diri untuk menyelenggarakan proses pembelajaran berbasis digital. Kemajuan teknologi informasi dan internet saat ini mengakibatkan sumber daya informasi digital sangat melimpah (Kurnianingsih dkk., 2017). Di sisi lain, perkembangan teknologi informasi diibaratkan seperti dua sisi mata uang yang memberikan efek positif dan negatif kepada masyarakat. Pembelajaran literasi digital tidak bisa dielakkan lagi

Penguasaan literasi dalam segala aspek kehidupan memang menjadi hal pokok dalam kemajuan peradaban suatu bangsa. Penduduk Indonesia memiliki kuantitas yang besar tetapi kualitas yang rendah padahal kuantitas dan kualitas perlu untuk diimbangi. Hal ini menunjukkan bahwa kualitas sumber daya manusia di Indonesia masih rendah bahkan mengalami penurunan dari tahun ke tahun. Salah satu faktor penurunan rendahnya kualitas sumber daya manusia ini adalah rendahnya pendidikan. Hal ini semakin diperburuk dengan masih dominanya budaya tutur (lisan) daripada budaya baca. Pada 
umumnya kemampuan penggunaan teknologi dan informasi dari perangkat digital membantu setiap pekerjaan agar efektif dan efesien dalam berbagai konteks kehidupan, seperti: akademik, karir, dan kehidupan sehari-hari (Gilster, 1997). Konsep literasi yang banyak mengalami perkembangan dan digunakan dalam berbagai bentuk, di antaranya literasi digital yaitu kemampuan untuk memahami dan menggunakan informasi dari berbagai sumber digital (A'yuni, 2015).

Berdasarkan uraian yang telah dikemukakan, dipandang penting menyampaikan pemikiran tentang tiga hal, yaitu (a) apa yang dimanksud dengan literasi digital?, (b) mengapa literasi digital diperlukan dalam membangun peradaban bangsa, dan (c) bagaimana mengembangkan kemampuan literasi digital?

\section{PEMBAHASAN}

\section{Literasi Digital}

$\begin{array}{crr}\text { Menurut } & \text { UNESCO, } & \text { literasi } \\ \text { merupakan } & \text { kemampuan } & \text { dalam }\end{array}$
mengidentifikasi, memahami, menafsirkan, menciptakan, berkomunikasi, menghitung dan menggunakan bahan cetak serta tulisan dalam kaitannya dengan berbagai pencapaian tujuan dalam mengembangkan pengetahuan serta potensi mereka, dan untuk berpartisipasi secara penuh dalam komunitas mereka serta masyarakat (A'yuni, 2015). Pendapat Gilster tersebut seolah-olah menyederhanakan media digital yang sebenarnya terdiri dari berbagai bentuk informasi sekaligus seperti suara, tulisan dan gambar. Oleh karena itu Eshet menekankan bahwa literasi digital seharusnya lebih dari sekedar kemampuan menggunakan berbagai sumber digital secara efektif. Literasi digital juga merupakan sebentuk cara berpikir tertentu (Eshet, 2004). Bawden menawarkan pemahaman baru mengenai literasi digital yang berakar pada literasi komputer dan literasi informasi (Bawden, 2001). Literasi komputer berkembang pada dekade 1980-an ketika komputer mikro semakin luas dipergunakan tidak saja di lingkungan bisnis namun juga masyarakat. Sedangkan literasi informasi menyebarluas pada dekade 1990an manakala informasi semakin mudah disusun, diakses, disebarluaskan melalui teknologi informasi berjejaring. Sedangkan Menurut Martin, literasi digital adalah gabungan dari beberapa bentuk literasi seperti: informasi, komputer, visual dan komunikasi (Martin, 2008). Menurut Gilster yang dikutip oleh A'yuni, literasi digital diharapkan dapat menjadi sebagai kemampuan dalam memahami serta menggunakan informasi dari berbagai format (A’yuni, 2015; Gilster, 1997). Gilster menjelaskan bahwa konsep literasi bukan hanya mengenai kemampuan untuk membaca saja melainkan membaca dengan makna dan mengerti. Literasi digital mencakup penguasaan ide-ide, bukan penekanan tombol. Jadi Gilster lebih menekankan pada proses berpikir kritis ketika berhadapan dengan media digital daripada kompetensi teknis sebagai keterampilan inti dalam literasi digital, serta menekankan evaluasi kritis dari apa yang ditemukan melalui media digital daripada keterampilan teknis yang diperlukan untuk mengakses media digital tersebut. Gilster mendefenisikan bahwa selain seni berpikir kritis, kompetensi yang dibutuhkan yaitu kemampuan mempelajari bagaimana menyusun pengetahuan, serta membangun 
sekumpulan informasi yang dapat diandalkan dari beberapa sumber yang berbeda (Gilster, 1997). Seseorang yang berliterasi digital perlu mengembangkan kemampuan untuk mencari serta membangun suatu strategi dalam menggunakan search engine guna mencari informasi yang ada serta bagaimana menemukan informasi yang sesuai dengan kebutuhan informasinya. Selain itu kemampuan penggunaan tekologi dan informasi dari perangkat digital membantu agar efektif dan efesien dalam berbagai konteks kehidupan, seperti : akademik, karir, dan kehidupan sehari-hari.

Menurut Martin, literasi digital merupakan kemampuan individu untuk menggunakan alat digital secara tepat sehingga ia terfasilitasi untuk mengakses, mengelola, mengintegrasikan, mengevaluasi, menganalisi sumber daya digital agar membangun pengetahuan baru, membuat media berekspresi, berkomunikasi dengan orang lain dalam situasi kehidupan tertentu untuk mewujudkan pembangunan sosial, dari beberapa bentuk literasi yaitu: komputer, informasi teknologi, visual, media dan komunikasi (Martin, 2008). Senanda dengan pendapat Bawden mengartikan bahwa literasi digital adalah kemampuan dalam menggunakan informasi dari berbagai sumber digital yang disajikan melalui komputer (Bawden, 2001). Literasi digital dapat diartikan sebagai kemampuan individu untuk menerapkan keterampilan fungsional pada perangkat digital sehingga ia dapat menemukan dan memilih informasi, berpikir kritis, berkreativitas, berkolaborasi bersama orang lain, berkomunikasi secara efektif, dan tetap menghiraukan keamanan elektronik serta konteks sosial-budaya yang berkembang (Hague \& Payton, 2010). Dari pengertian di atas dapat disimpulkan bahwa literasi digital bukan sekedar menggunakan perangkat digital saja tetapi literasi digital diharapkan mampu untuk menemukan dan memilih informasi, berpikir kritis, berkreativitas, berkolaborasi bersama orang lain, berkomunikasi secara efektif, dan tetap menghiraukan keamanan elektronik serta konteks sosial-budaya yang berkembang.

Berbasis pada literasi komputer dan informasi, Bawden menyusun konsep literasi digital. Lebih komprehensif dibandingkan Glitser, Bawden menyebutkan bahwa digital literasi menyangkut beberapa aspek berikut ini:

1) Perakitan pengetahuan yaitu kemampuan membangun informasi dari berbagai sumber yang terpercaya.

2) Kemampuan menyajikan informasi termasuk di dalamnya berpikir kritis dalam memahami informasi dengan kewaspadaan terhadap validitas dan kelengkapan sumber dari internet.

3) Kemampuan membaca dan memahami materi informasi yang tidak berurutan (non sequential) dan dinamis.

4) Kesadaran tentang arti penting media konvensional dan menghubungkannya dengan media berjaringan (internet).

5) Kedadaran terhadap akses jaringan orang yang dapat digunakan sebagai sumber rujukan dan pertolongan.

6) Penggunaan saringan terhadap informasi yang datang.

7) Merasa nyaman dan memiliki akses untuk mengkomunikasikan dan mempublikasikan informasi.

Jika menilik pendapat Bawden di atas maka digital literasi lebih banyak dikaitkan dengan ketrampilan teknis mengakses, merangkai, memahami dan menyebarluaskan informasi. 
Faktor Faktor Yang Mempengaruhi Literasi Digital

Literasi digital dapat diartikan sebagai kemampuan individu untuk menerapkan keterampilan fungsional pada perangkat digital sehingga ia dapat menemukan dan memilih informasi, berpikir kritis, berkreasi, berkolaborasi bersama orang lain, berkomunikasi secara efektif, dan tetap menghiraukan keamanan elektronik serta konteks sosial-budaya yang berkembang (Hague \& Payton, 2010).

Dalam literasi digital kita harus memahami faktor faktor penting agar penyaringan informasi berjalan dengan baik dan benar. Berikut beberapa faktor yang mempengaruhi literasi digital :

\section{- KETERAMPILAN FUNGSIONAL (FUNCTIONAL SKILLS).}

Keterampilan fungsional adalah kemampuan dan kompetensi teknis yang diperlukan untuk menjalankan berbagai alat digital dengan mahir. Bagian penting dari pengembangan keterampilan fungsional adalah mampu mengadaptasi keterampilan ini untuk mempelajari cara menggunakan teknologi baru. Fokusnya merupakan apa yang dapat dilakukan dengan alat digital dan apa yang perlu dipahami untuk menggunakannya secara efektif.

\section{- KOMUNIKASI DAN INTERAKSI}

Komunikasi dan interaksi yang
melibatkan percakapan, diskusi, dan
membangun ide satu sama lain untuk
menciptakan pemahaman bersama.
Kemampuan berkolaborasi merupakan
bekerja dengan baik bersama orang lain untuk
bersama-sama meciptakan makna dan
pegetahuan. Mendukung literasi digital pada

kaum muda melibatkan pengembangan pemahaman mereka tentang bagaimana menciptakan secara kolaboratif dalam penggunaan teknologi digital serta bagaimana teknologi digital dapat secara efektif mendukung proses kolaboratif di dalam kelas dan dunia yang lebih luas.

\section{- BERPIKIR KRITIS}

Perbedaan hakiki antara manusia dengan mahluk lainnya terletak pada kemampuannya berpikir. Manusia diberi akal. Dengan akalnya manusia selalu berpikir untuk mengenali sesuatu, bertanya tentang dirinya dan alam di sekitarnya (Suradika, 2000). Dengan akalnya juga manusia dapat berpikir kritis. Pemikiran kritis melibatkan perubahan, analisis, atau pemrosesan informasi data atau gagasan yang diberikan untuk menafsirkan makna pada pengembangan wawasan. Seperti, asumsi mendasar yang mendukung proses pembuatan informasi yang dapat diterima oleh akal. Kemudian sebagai komponen literasi digital juga melibatkan kemampuan dalam menggunakan keterampilan penalaran untuk terlibat dengan media digital dan kontenya serta mempertanyakan, menganalisis dan mengevaluasi. Keterlibatan menuntut untuk berpikir kritis dengan alatalat digital.

\section{Pembelajaran Literasi Digital}

Di Indonesia, kegiatan literasi media lebih didorong oleh kekhawatiran bahwa media dapat menimbulkan pengaruh negatif. Oleh karena itu, banyak kalanngan seperti orang tua, guru, LSM dan lainnya berusaha keras menemukan solusi untuk mengurangi dan mencegah dampak negatif dari media. 
Penjelasan di atas mendudukan literasi digital dengan jelas. Keterampilan ini dapat meningkatkan kemampuan seseorang berhadapan dengan media digital baik mengakses, memahami konten, menyebarluaskan, membuat bahkan memperbarui media digital untuk pengambilan keputusan dalam hidupnya. Jika seseorang memiliki ketrampilan ini maka ia dapat memanfaatkan media digital untuk aktivitas produktif dan pengembangan diri bukan untuk tindakan konsumtif bahkan destruktif.

Kesadaran kritis, diskusi, pilihan kritis, dan aksi sosial merupakan hal terpenting dalam literasi digital. Namun kesadaran kritis yang paling utama memberikan manfaat bagi khalayak untuk mendapat informasi secara benar terkait coverage media dengan membandingkan antara media yang satu dengan yang lain secara kritis; lebih sadar akan pengaruh media dalam kehidupan sehari-hari; menginterpretasikan pesan media; membangun sensitivitas terhadap programprogram sebagai cara mempelajari kebudayaan; mengetahui pola hubungan antara pemilik media dan pemerintah yang memengaruhi isi media; serta mempertimbangkan media dalam keputusankeputusan individu. Kesadaran kritis khalayak atas realitas media inilah yang menjadi tujuan utama literasi media. Ini karena media bukanlah entitas yang netral. Ia selalu membawa nilai, baik ekonomi, politik, maupun budaya. Keseluruhannya memberikan dampak bagi individu bagaimana ia menjalani kehidupan seharihari. Literasi media hadir sebagai benteng bagi khalayak agar kritis terhadap isi media, sekaligus menentukan informasi yang dibutuhkan dari media. Literasi media diperlukan di tengah kejenuhan informasi, tingginya terpaan media, dan berbagai permasalahan dalam informasi tersebut yang mengepung kehidupan kita sehari-hari. Untuk itu, khalayak harus bisa mengontrol informasi atau pesan yang diterima. Literasi media memberikan panduan tentang bagaimana mengambil kontrol atas informasi yang disediakan oleh media. Semakin media literate seseorang, maka semakin mampu orang tersebut melihat batas antara dunia nyata dengan dunia yang dikonstruksi oleh 19 media. Orang tersebut juga akan mempunyai peta yang lebih jelas untuk membantu menentukan arah dalam dunia media secara lebih baik. Pendeknya, semakin media literate seseorang, semakin mampu orang tersebut membangun hidup yang kita inginkan alih-alih membiarkan media membangun hidup kita sebagaimana yang media inginkan.

\section{KESIMPULAN}

Berdasarkan uraian di atas, dapat disimpulkan beberapa hal sebagai berikut:

1) Literasi digital adalah suatu bentuk kemampuan untuk mendapatkan, memahami dan menggunakan informasi yang berasal dari berbagai sumber dalam bentuk digital. Literasi digital seharusnya lebih dari sekedar kemampuan menggunakan berbagai sumber digital secara efektif, tetapi juga merupakan sebentuk cara berpikir tertentu yang berakar pada literasi komputer dan literasi informasi.

2) Pengembangan kemampuan literasi digital dapat dilakukan dengan peningkatan bebrapa kemampuan, antara lain (a) keterampilan 
fungsional, yaitu kemampuan dan kompetensi teknis yang diperlukan untuk menjalankan berbagai alat digital dengan mahir. Bagian penting dari pengembangan keterampilan fungsional adalah mampu mengadaptasi keterampilan ini untuk mempelajari cara menggunakan teknologi baru. Fokusnya merupakan apa yang dapat dilakukan dengan alat digital dan apa yang perlu dipahami untuk menggunakannya secara efektif, (b) Komunikasi dan interaksi yang melibatkan percakapan, diskusi, dan membangun ide satu sama lain untuk menciptakan pemahaman bersama, (c) kemampuan berkolaborasi merupakan bekerja dengan baik bersama orang lain untuk bersama-sama meciptakan makna dan pegetahuan. dan (d) kekampuan berpikir kritis, yakni kemampuan menggunakan keterampilan penalaran untuk terlibat dengan media digital dan kontennya serta mempertanyakan, menganalisis dan mengevaluasi.

3) Dengan adanya kemampuan literasi digital masyarakat dapat mengakses, memilah dan memilih serta memahami berbagai jenis informasi yang dapat digunakan untuk meningkatkan kualitas hidup, Pendek kata, literasi digital membuat seseorang dapat menyaring informasi di lingkungannya dengan baik. Sehingga ia dapat berpartisipasi dalam kehidupan sosial dengan lebih baik. Oleh karenanya literasi digital perlu terus dikembangkan agar masyarakat pengguna internet selalu bertanggung jawab atas informasi yang mereka peroleh, termasuk di dalamnya menjaga keamanan data dan privasi mereka di internet.

\section{REFERENSI}

A’yuni, Q. Q. (2015). Literasi Digital Remaja Di Kota Surabaya: Studi Deskriptif tentang Tingkat Kompetensi Literasi Digital pada Remaja SMP, SMA dan Mahasiswa di Kota Surabaya. LibriNet, $\quad 4(2), \quad$ 1-15. https://repository.unair.ac.id/17685/
Afandi, Junanto, T., \& Afriani, R. (2016). Implementasi Digital-Age Literacy Dalam Pendidikan Abad 21 Di Indonesia. Prosiding Seminar Nasional Pendidikan Sains, 3(0), 2016-2113.

https:/jurnal.fkip.uns.ac.id/index.php /snps/article/view/9820

Akbar, M. F., \& Anggraeni, F. D. (2017). Teknologi Dalam Pendidikan: Literasi Digital dan Self-Directed Learning pada Mahasiswa Skripsi. Indigenous: Jurnal Ilmiah Psikologi, 2(1). https://doi.org/10.23917/indigenous.v $1 \mathrm{i} 1.4458$

Bawden, D. (2001). Information and digital literacies: A review of concepts. Journal of Documentation, 57(2), 218-259.

https://doi.org/10.1108/EUM0000000 007083

Eshet, Y. (2004). Digital Literacy: A Conceptual Framework for Survival Skills in the Digital era. Journal of Educational Multimedia and Hypermedia, 13(1), 93-106. http://www.editlib.org/p/4793/\%5Cnf iles/364/Eshet and Eshet - 2004 Digital Literacy A Conceptual Framework for Survi.pdf\%5Cnfiles/459/4793.html

Friedman, T. (2007). The world is flat : a brief history of the twenty-first century. In The World is Flat: a Brief History of Twenty-First Century. Picador/Farrar Straus and Giroux;Distributed by Holtzbrinck Publishers.

Gilster, P. (1997). Digital literacy. Wiley Computer Pub.

Hague, A. C., \& Payton, S. (2010). Digital literacy across the curriculum. In Futurelab (p. 58). http://www2.futurelab.org.uk/resourc es/documents/handbooks/digital liter acy.pdf $\% 5$ Cnwww.futurelab.org $\% 5 \mathrm{C}$ nwww.futurelab.org.uk/\%5Cnproject $\mathrm{s} /$ digital-participation

Kurnianingsih, I., Rosini, R., \& Ismayati, N. (2017). Upaya Peningkatan Kemampuan Literasi Digital Bagi Tenaga Perpustakaan Sekolah dan Guru di Wilayah Jakarta Pusat Melalui Pelatihan Literasi Informasi. Jurnal Pengabdian Kepada Masyarakat (Indonesian Journal of 
Community Engagement), 3(1), 61. https://doi.org/10.22146/jpkm.25370

Martin, A. (2008). Digital Literacy and the "Digital Society." In C. Lankshear \& M. Knobel (Eds.), Digital Literacies: Concepts, Policies \& Practices (pp. 151-176). Peter Lang https://pages.ucsd.edu/ bgoldfarb/co mt109w10/reading/Lankshear-

Knobel_et_al-DigitalLiteracies.pdf

Pilliang, Y. (2012). MASYARAKAT INFORMASI DAN DIGITAL: Teknologi Informasi dan Perubahan
Sosial. Jurnal Sosioteknologi, 11(27), 143-155.

Suradika, A. (2000). Metode Penelitian Sosial. UMJ Press.

Umam, Kaiful; Zaini, I. (2013). Penerapan Media Digital Dalam Pembelajaran Apresiasi Batik Kelas X SMA Negeri 1 Blega. Jurnal Pendidikan Seni Rupa, l(1), 100-105. https://jurnalmahasiswa.unesa.ac.id/i ndex.php/va/article/view/9788 